\title{
Assessment of Pollution Status of Urban Wetlands of Gurugram, India, using Sediment Geochemistry
}

\author{
AROHI DIXIT $^{1}$ AND N. SIVA SIDDAIAH ${ }^{2 *}$ \\ 1,2 School of Environmental Sciences, Jawaharlal Nehru \\ University, New Delhi - 110 067, India (*correspondence: \\ nssiddaiah@gmail.com)
}

Monitoring the health of shallow urban wetlands and their conservation is one of the most important strategies to deal with severe water-related issues blooming in urban areas. Different land-use activities adjacent to wetlands, directly and indirectly, affect the wetland ecosystem by altering its inputs such as addition of sewage, industrial effluents, stormwater, organic debris, nutrients, dissolved carbon, and contaminants such as heavy metals. The effects of such additions are much severe on shallow depressional wetlands where inputs settle very quickly. In this study, sediment geochemistry has been used as a tool to investigate the health status of four urban wetlands (Lost, Sultanpur, Damdama, and Basai) in Gurugram, a satellite city in Delhi NCR, India, facing rapid urban growth. For the study, surface sediments were collected and studied for various parameters such as $\mathrm{pH}$ and EC (1:5 soil: water suspension method), major and trace elements (XRF and ICP-AES), silt-clay ratio (hydrometer technique) and $\mathrm{C} / \mathrm{N}$ ratio (CHNS). Pollution assessment was carried out using enrichment factor (EF), geo-accumulation index (Igeo) and pollution load index (PLI). Low $\mathrm{C} / \mathrm{N}$ ratios and $813 \mathrm{C}$ and $\delta 13 \mathrm{~N}$, which serve as a robust indicator of wetland eutrophication, suggest the highest contamination level of sediments of Basai wetland as compared to sediments of other wetlands. Contaminated sediments in Basai wetlands may be attributed to high degree of anthropogenic influence (continuous sewage addition, construction of roads, wastewater from water treatment plants, etc.) as compared to other three wetlands. It is an alarming bell for water conservationists and needs immediate attention. 